\title{
Resistance to cisplatin-induced apoptosis via PI3K-dependent survivin expression in a rat hepatoma cell line
}

\author{
HIROYUKI ASECHI, ETSURO HATANO, TAKASHI NITTA, MASAHARU TADA, \\ KEIKO IWAISAKO, NOBUYUKI TAMAKI, HIROMITSU NAGATA, MASATO NARITA, \\ ATSUKO YANAGIDA, IWAO IKAI and SHINJI UEMOTO
}

Department of Surgery, Graduate School of Medicine, Kyoto University, Kyoto, Japan

Received January 7, 2010; Accepted March 4, 2010

DOI: 10.3892/ijo_00000656

\begin{abstract}
Hepatocellular carcinoma (HCC) is known to be resistant to chemotherapy. Survivin, a member of the inhibitor of apoptosis proteins, is overexpressed in most cancers but is absent in most normal adult tissue. The aim of this study was to investigate whether expression of survivin contributes to resistance to cisplatin-induced apoptosis. We confirmed induction of survivin expression in hepatoma in the $\mathrm{N}$ diethylnitrosamine (DEN) induced rat and in the rat hepatoma cell line (K-251). We examined cell proliferation after treatment with cisplatin (CDDP) in the presence and absence of siRNA or the phosphatidylinositol 3-kinase (PI3K) inhibitor LY294002 to suppress survivin or PI3K/ Akt, respectively. Survivin was expressed in DEN-induced rat HCC with RT-PCR and Western blotting. Expression of survivin was observed primary in the nuclei and in the cytoplasm with immunohistochemistry. However, survivin was not detected in non-tumor tissues. Expression of survivin was also observed primarily in the nuclei and in the cytoplasm of the K-251 rat hepatoma cell line. CDDP induced survivin expression, which was blocked by siRNA. LY294002 also attenuated survivin expression induced by CDDP. Our results indicate that survivin expression via PI3K contributes to resistance to CDDP-induced apoptosis in a rat hepatoma cell line.
\end{abstract}

\section{Introduction}

Hepatocellular carcinoma (HCC) is one of the most common cancers in the world, accounting for approximately $6 \%$ of all human cancers and 1 million deaths annually, with an estimated number of new cases of over 500,000 per year $(1,2)$. Although the clinical management for early-stage HCC has

Correspondence to: Dr Etsuro Hatano, Department of Surgery, Graduate School of Medicine Kyoto University, 54 Kawahara-cho Shogoin Sakyo-ku Kyoto, 606-8507, Japan

E-mail: etsu@kuhp.kyoto-u.ac.jp

Key words: survivin, apoptosis, siRNA, hepatocellular carcinoma, cisplatin improved significantly, the prognosis of HCC is still extremely poor and is the third highest cause of cancer-related mortality. HCC exhibits resistance to chemotherapy, such as cisplatin (CDDP). Therefore, investigating and finding new treatment for HCC is important.

Cell proliferation is determined not only by the rate of cell growth but also by the rate of cell loss. Apoptosis is a major component of this regulatory process, which consists of 2 converging cascades 'death-receptor pathway' and 'mitochondrial pathway' $(3,4)$. The death-receptor pathway is triggered by the interaction of death ligands of the tumor necrosis factor family with their cognate receptors that assemble the death-inducing signaling complex, resulting in activation of caspase-8. The mitochondrial pathway involves mitochondria that release apoptogenic factors, such as cytochrome c and Smac/DIABLO, in response to noxious stimuli.

Members of the IAP family are known to inhibit death receptors and the mitochondrial pathway by acting as endogenous inhibitors of caspases $(4,5)$. Survivin is a bifunctional protein that controls cell division and inhibits apoptosis (6). The mechanism by which survivin inhibits apoptosis remains in dispute. While it is capable of binding to effector caspases under cell-free conditions, under more physiological conditions it inhibits apoptosis by binding to the second mitochondrial activator of caspases (Smac) (7). Survivin is present in only small amounts in terminally-differentiated normal cells, but is found to be prominently overexpressed in a variety of tumors, including cancers of the lung, stomach, breast, melanoma, pancreas, esophagus and colon (8-15). Overexpression of survivin has been identified as a negative prognostic factor in various cancer types $(8,14,16)$, and is implicated in resistance to the induction of apoptosis by anti-cancer agents (17).

Despite increasing evidence in support of survivin as a promising target for molecular intervention, the mechanism of survivin overexpression in HCC and its implication in drug resistance remain to be investigated. Recent reports have demonstrated that survivin was up-regulated via the PI3K/ Akt pathway in myeloid leukemia cells (18), endothelial cells (19), and prostate cancer cells (20). Furthermore, Akt is also activated in response to stress by UV irradiation and chemotherapy (21-23). Whether activation of Akt constitutes a physiological stress response that enables cancer cells to evade apoptosis by up-regulation of survivin remains to be demonstrated. 
The purpose of this study was to clarify whether survivin is overexpressed in rat HCCs and if expression of survivin contributes to resistance to cisplatin-induced apoptosis in HCC cells. We investigated alterations in cell morphology and proliferation in HCC cells in the presence and absence of siRNA against survivin and a PI3K inhibitor.

\section{Materials and methods}

Rat DEN-induced HCC and HCC cell lines. Rat HCC was induced with N-diethylnitrosamine (DEN, Sigma, St. Louis, MO, USA). SD rats (4-week-old males, weighing $100 \mathrm{~g}$; SLC, Hamamatsu, Japan) were provided with 100 ppm DEN ad libitum in drinking water for 8 weeks and were maintained for an additional 4 weeks without administration of DEN (24-26).

The DEN-induced rat HCC cell line K-251 was obtained from Cell Resource Center for Biomedical Research Institute of Development, Aging and Cancer Tohoku University. The cell line K-251 was grown in RPMI-1640 with L-glutamine (Invitrogen Corporation, Gibco 21875-034) supplemented with $10 \% \mathrm{FBS}$ and $1 \%(\mathrm{w} / \mathrm{v})$ penicillin/streptomycin $(\mathrm{PC} / \mathrm{SM})$ at $37^{\circ} \mathrm{C}$ in a humidified atmosphere containing $5 \% \mathrm{CO}_{2}$. Cells were treated with CDDP (Nippon Kayaku, Tokyo, Japan) and LY294002 (Calbiochem-Novabiochem. Corp.). Cells were treated with the PI3K inhibitor LY294002 dissolved in DMSO.

Quantitative real-time RT-PCR. Total RNA was extracted from the liver tissues or cultured cells with TRIzol (Invitrogen, Tokyo, Japan). Total RNA (2 $\mu \mathrm{g})$ was reverse transcribed to cDNA with an Omniscript RT kit (Qiagen, Tokyo, Japan) with oligo $(\mathrm{dT})_{8-12}$ primers (Invitrogen). Real-time PCR was performed with a QuantiTect SYBR Green PCR kit (Qiagen) and an ABI PRISM 7700 Sequence Detection System (Applied Biosystems, Tokyo, Japan). RT-PCR was performed with an initial step at $95^{\circ} \mathrm{C}$ for $15 \mathrm{~min}$, followed by 40 cycles at $95^{\circ} \mathrm{C}$ for $20 \mathrm{sec}, 59^{\circ} \mathrm{C}$ for $30 \mathrm{sec}$, and $72^{\circ} \mathrm{C}$ for $1 \mathrm{~min}$ with a final step at $72^{\circ} \mathrm{C}$ for $10 \mathrm{~min}$. Two specific primers were used to identify survivin (Forward: 5'-TAAGCCACTTGTC CCAGCTT-3'; Reverse: 5'-CTCATCCACTCCCTTCCTC A-3') and G3PDH (Forward: 5'-ACCACAGTCCATGCCAT CAC-3'; Reverse: 5'-TCCACCACCCTGTTGCTGTA-3') The expression levels were calculated after conversion to numerical values by ABI PRISM 7700 SDS software and are expressed as ratios relative to the expression of G3PDH.

Western blot analysis. Frozen liver tissues or cultured hepatocytes were homogenized in lysis buffer containing $50 \mathrm{mM}$ Tris- $\mathrm{HCl}, 2 \%$ sodium dodecylsulfate and $10 \%$ glycerol, and then boiled for $2 \mathrm{~min}$. After the protein concentration in the sample was determined, $0.1 \%$ bromophenol blue and 6\% 2mercaptoethanol were added. Subsequently, $20 \mu \mathrm{g}$ of each sample was electrophoresed and transferred onto PVDF membranes (Immobilon, Millipore, Billerica, MA). The membranes were blocked with 5\% skim milk in PBS and incubated at $4^{\circ} \mathrm{C}$ overnight with the following primary antibodies and dilutions: anti-survivin antibody (no. sc-10811; Santa Cruz Biotechnology, Santa Cruz, CA; 1:200); anticleaved caspase-3 antibody (no. 9661; Cell Signaling Technology; 1:1000); anti-PARP antibody (no. 9542; Cell Signaling
Technology; 1:1000); anti-phospho Akt antibody (no. 9271; Cell Signaling Technology; 1:500); anti-XIAP antibody (no. 2042; Cell Signaling Technology; 1:1000); anti- $\alpha$-tubulin antibody (no. CP06; Calbiochem; 1:1000); and anti-GAPDH antibody (no. sc-20357; Santa Cruz Biotechnology; 1:200). After washing, the membranes were incubated with secondary antibodies conjugated with horseradish peroxidase. Chemiluminescence detection was performed using ECL Western Blotting Detection Regents (Amersham, Buckinghamshire, UK), according to the manufacturer's instructions. The intensity of the band was quantified with National Institutes of Health Image (NIH-Image) and normalized to GAPDH as an internal control.

Immunohistochemistry. The specimens were fixed in $10 \%$ formalin and embedded in paraffin. They were subsequently deparaffinized and endogenous peroxidase was quenched with $0.3 \%$ hydrogen peroxide in methanol at room temperature for $15 \mathrm{~min}$. The antigen was retrieved by incubation in citric acid buffer at $90^{\circ} \mathrm{C}$ for $20 \mathrm{~min}$. After blocking, the sections were incubated with primary antibody recognizing survivin (no. sc10811; Santa Cruz Biotechnology, Santa Cruz, CA; 1:200 dilution) overnight at $4^{\circ} \mathrm{C}$ and then with labeled polymer in an Envision+ System HRP (Dako, Tokyo, Japan) at room temperature for $1 \mathrm{~h}$. The sections were examined after incubation with a Liquid DAB Substrate Chromogen System (Dako) for $2 \mathrm{sec}$.

siRNA for survivin transfection. siRNA with the sequence GGACUUAAGCACUGAGGAA targeting the survivin mRNA and the negative control sequence ATCCGCGCGAT AGTACGTA were purchased from B-Bridge International, Inc. Cells were transfected with Lipofectamine 2000 (Invitrogen) according to the reverse transfection method (27) using Opti-MEM (Invitrogen Corp., Gibco 31985-070) and Insulin-Transferrin-Selenium (ITS; Invitrogen Corp., Gibco 41400-045). Briefly, cells were plated at $20 \times 10^{4}$ cells/well in 6 -well plates. Cells were transfected for $6 \mathrm{~h}$, respectively. After transfection, cells were grown in RPMI-1640 with Lglutamine supplemented with ITS and $1 \%(\mathrm{w} / \mathrm{v})$ penicillin/ streptomycin. Samples were collected $24 \mathrm{~h}$ after transfection. Experiments were repeated at least 3 times.

Cell proliferation assay. Cell proliferation was determined using the Cell Counting kit-8 (CCK-8; Dojindo, Kumamoto, Japan) to count living cells. Cells were cultured and treated in 24-well plates. At 0, 12, 24, 48 and $72 \mathrm{~h}$, the CCK-8 was used to determine cell proliferation according to the manufacturer's instruction.

Statistical analysis. All data are expressed as the means \pm SEM, and the statistical significance of differences between groups was assessed by Mann-Whitney U-test. $\mathrm{P}<0.05$ were regarded as statistically significant.

\section{Results}

Expression of survivin in DEN-induced hepatoma and in the rat hepatoma cell line. We first used RT-PCR to investigate the level of survivin messenger RNA (mRNA) in DEN-induced 
A
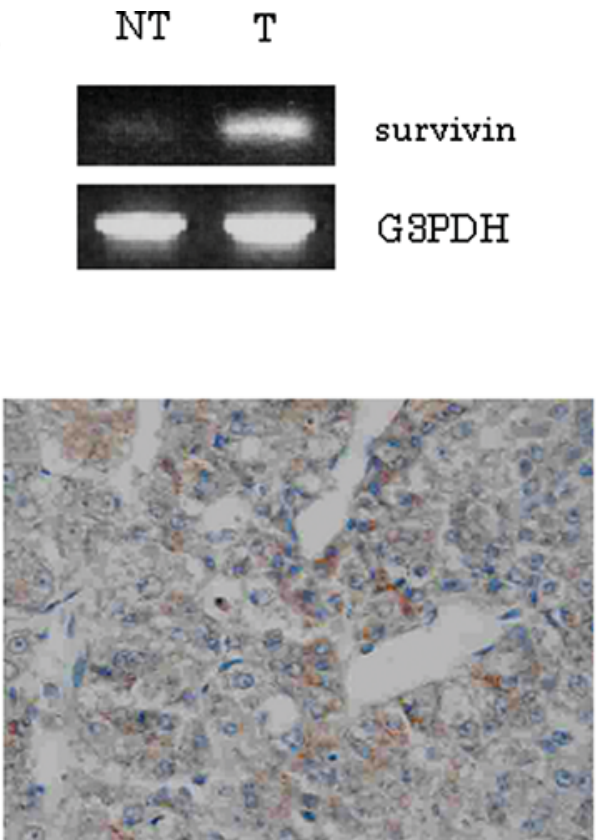

B

survivin

G3PDH
NT T

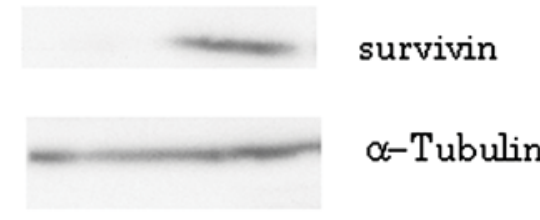

$\mathrm{D}$

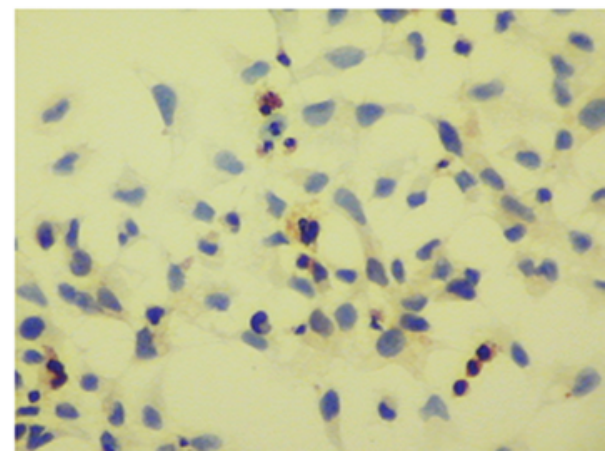

Figure 1. Expression of survivin in DEN-induced rat HCC. (A) RT-PCR of survivin mRNA in the non-tumor area of the rat liver and in rat HCC. (B) Western blot analysis of survivin protein in the non-tumor area of the rat liver and in rat HCC. (C) Immunohistochemical staining of survivin in rat HCC. Original magnification, x200. (D) Immunocytochemical staining of survivin in the DEN-induced rat hepatoma cell line K-251. Original magnification, x200.

rat HCC. A 75-bp fragment of survivin was detected in rat HCC (Fig. 1A). However, survivin mRNA was faintly detected in non-tumor tissues. Furthermore, a $16.5 \mathrm{kDa}$ fragment of survivin protein was detected in rat $\mathrm{HCC}$ with Western blotting (Fig. 1B), while survivin was not detected in non-tumor tissues. We performed immunohistochemical staining to determine the cellular localization of survivin. Expression of survivin was observed primarily in the nuclei and in the cytoplasm of HCC cells. In contrast, survivin was not expressed in the adjacent non-cancer tissues (Fig. 1C). Furthermore, we examined the survivin expression in rat hepatoma cell line (K-251) derived from DEN-induced HCC using immunocytochemical staining. Expression of survivin was observed primarily in the nuclei and in the cytoplasm (Fig. 1D).

Down-regulation of survivin by siRNA in the rat hepatoma cell line. In rat HCC cells, the efficiency of transfection was about $80-90 \%$, using red-labeled double-stranded RNA (dsRNA) oligomer by Lipofectamine 2000 (data not shown). Real-time PCR demonstrated that transfection with siRNA targeting survivin attenuated the expression of survivin mRNA to $68.1 \pm 8.5 \%$ of the expression level in cells transfected with negative control siRNA (Fig. 2A). Similarly, Western blotting showed that survivin expression was inhibited to $34.5 \pm 7.5 \%$ of control cells (Fig. 2B). The CCK-8 assay showed that the cell number decreased to $10.6 \pm 7.8 \%$ and $62.7 \pm 6.1 \%$ at 24 and $48 \mathrm{~h}$ after transfection, respectively, compared with control cells (Fig. 2C). These results indicate that transfection with siRNA significantly inhibited cell proliferation.

CDDP treatment up-regulates survivin expression and the silencing of RNA for survivin sensitizes CDDP-induced apoptosis in cancer cells. Treatment with CDDP induced overexpression of survivin protein in K-251 cells $(189.6 \pm 26.1 \%$ expression relative to cells without CDDP). Similarly, the induction of survivin was observed in cells transfected with negative control siRNA and siRNA against survivin (167.7 $\pm 26.9 \%, 149.5 \pm 23.9 \%$, respectively) (Fig. 3).

We examined fluorescence staining of nuclei using Hoechst 33342 and propidium iodide (PI) at $12 \mathrm{~h}$ after transfection with siRNA and treatment with CDDP. Irregular staining of the nuclei, nuclear fragmentation, and blebbing phenomenon were observed in cells treated with siRNA for survivin and CDDP, indicating apoptotic cell death (Fig. 4A). Percentage of apoptotic cells treated with negative control siRNA, negative control siRNA + CDDP, siRNA for survivin, siRNA for survivin + CDDP were $2.70 \pm 0.91 \%, 8.47 \pm 0.77 \%$, $25.74 \pm 6.57 \%, 33.83 \pm 5.88 \%$, respectively (Fig. 4B). The CCK-8 assay showed that $48 \mathrm{~h}$ after transfection with siRNA for survivin and treatment with CDDP cell proliferation was attenuated to $85.69 \pm 1.80 \%$ compared with cells transfected with negative control siRNA (Fig. 4C). Similarly, $48 \mathrm{~h}$ after transfection with siRNA for survivin and treatment with CDDP cell proliferation was attenuated to $78.15 \pm 1.12 \%$ compared with CDDP alone (data not shown).

siRNA for survivin induces caspase activation. Western blot analysis demonstrated that expression of cleaved caspase-3 was up-regulated in cells treated with siRNA for survivin compared to those treated with negative control siRNA. Similarly, siRNA for survivin increased the expression of cleaved caspase- 3 in cells treated with CDDP, compared with those treated with negative control siRNA (Fig. 5A). Furthermore, expression of cleaved PARP was also upregulated in cells treated with siRNA for survivin compared to those treated with negative control siRNA, in cells treated with/without CDDP (Fig. 5B). CDDP up-regulated the expression of phospho-Akt in cells treated with negative 
A
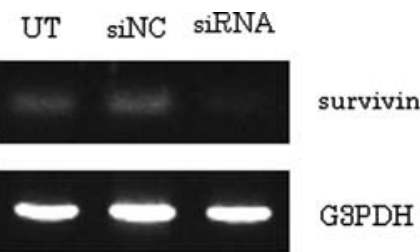

B

UT SINC siRNA

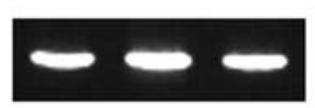

G3PDH
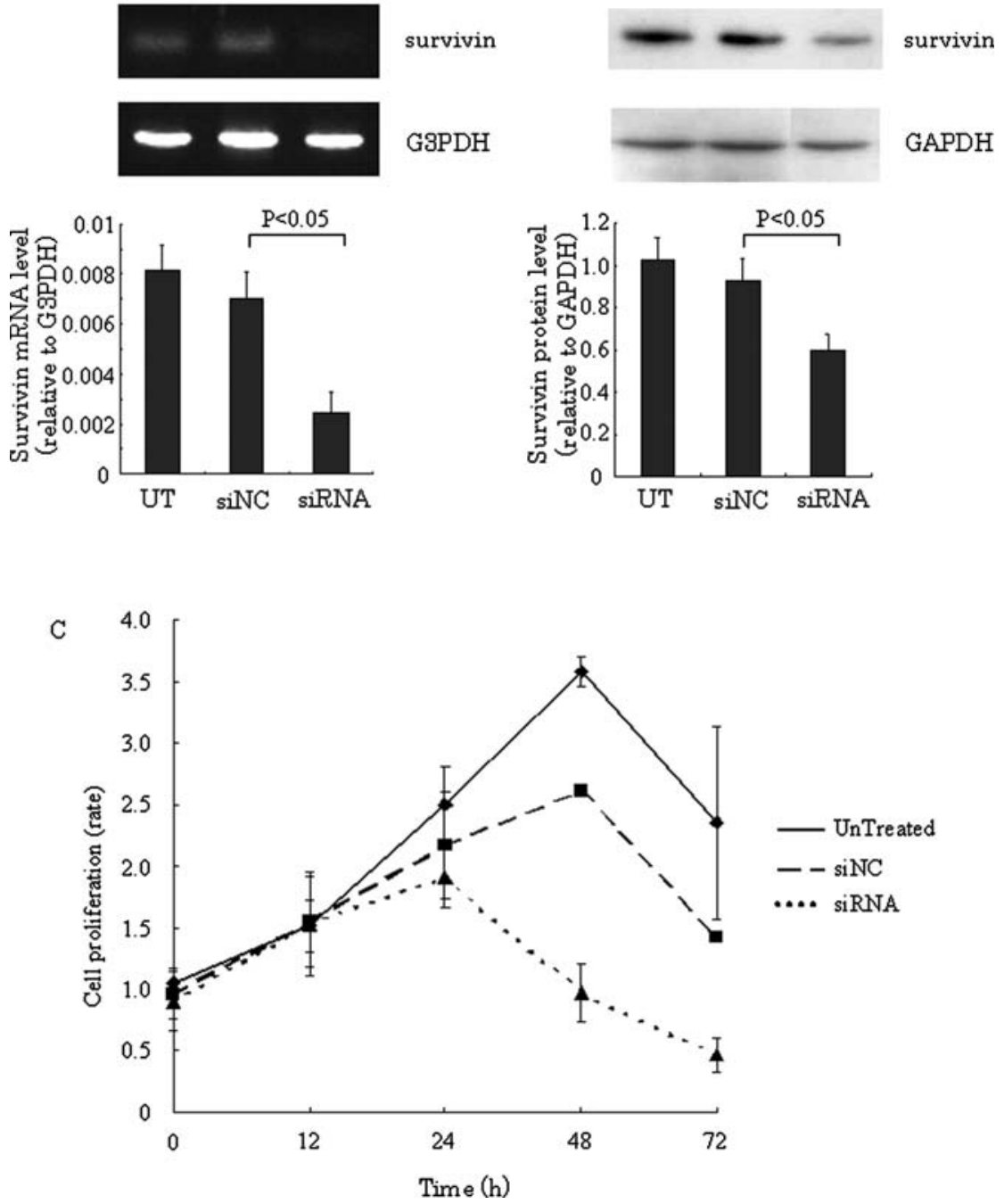

Figure 2. Down-regulation of survivin by siRNA in the DEN-induced rat hepatoma cell line. (A) Quantitative real-time PCR of survivin mRNA in un-treated HCC cells, in HCC cells treated with negative control siRNA and in HCC cells treated with siRNA for survivin. Data are expressed as the mean \pm SEM ( $=5$ ). (B) Western blot analysis of survivin protein in un-treated HCC cells, in HCC cells treated with negative control siRNA and in HCC cells treated with siRNA for survivin. Data are expressed as the mean \pm SEM $(n=4)$. (C) CCK-8 cell proliferation assay of un-treated HCC cells, HCC cells treated with negative control siRNA, and HCC cells treated with siRNA for survivin. Data are expressed as the mean \pm SEM $(n=3)$.

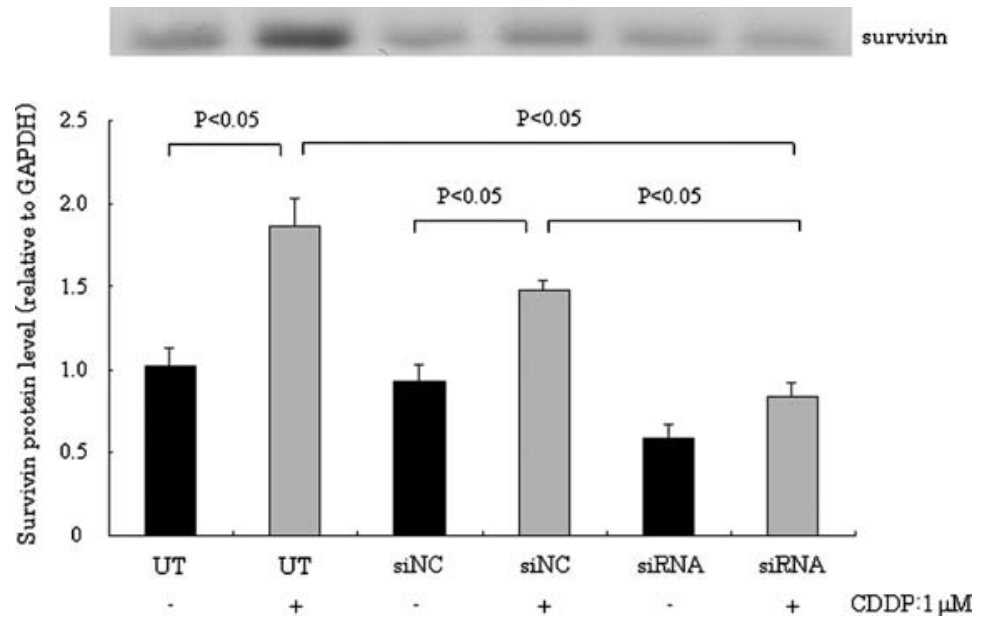

Figure 3. CDDP up-regulates survivin expression. Western blot analysis of survivin protein in untreated HCC cells, HCC cells treated with CDDP $(1 \mu \mathrm{M})$, HCC cells treated with negative control siRNA $(50 \mu \mathrm{M})$, HCC cells treated with negative control siRNA $(50 \mu \mathrm{M})+\mathrm{CDDP}(1 \mu \mathrm{M})$, HCC cells treated with siRNA for survivin $(50 \mu \mathrm{M})$, and HCC cells treated with siRNA for survivin $(50 \mu \mathrm{M})+\operatorname{CDDP}(1 \mu \mathrm{M})$. Data are expressed as the mean $\pm \operatorname{SEM}(\mathrm{n}=4)$. 
Hoechst 33342
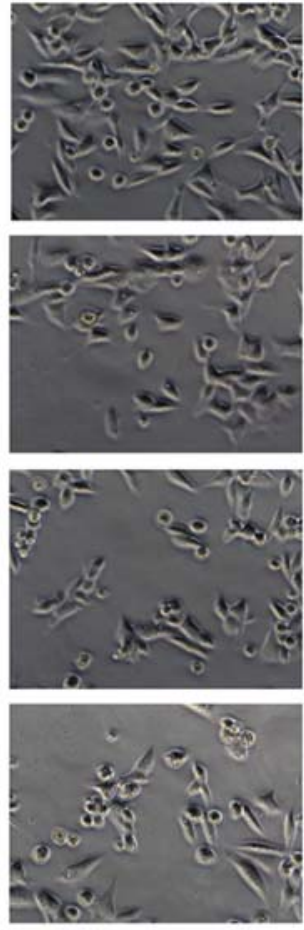

A

B

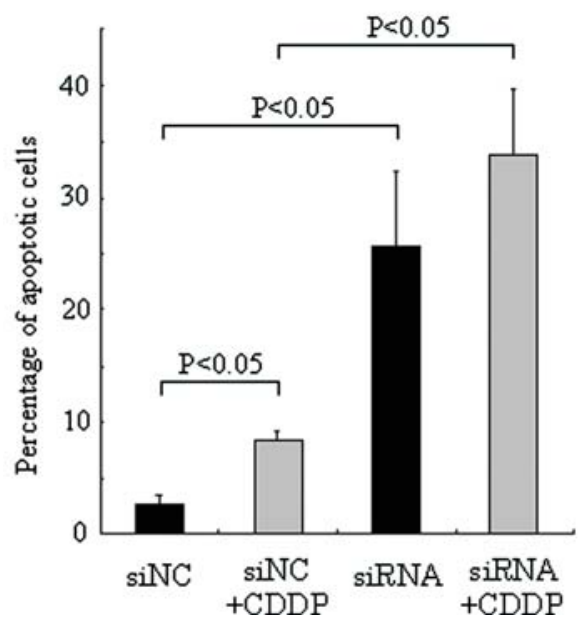

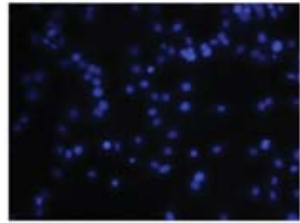
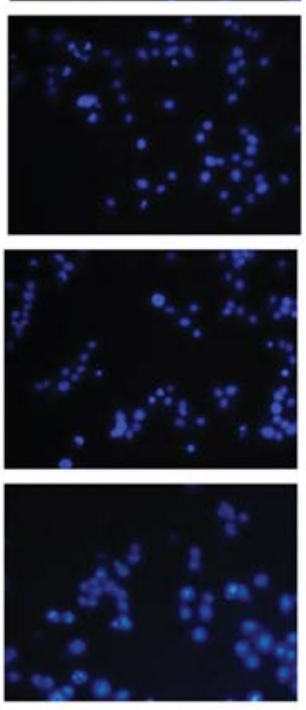

PI

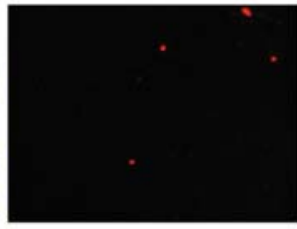

siNC

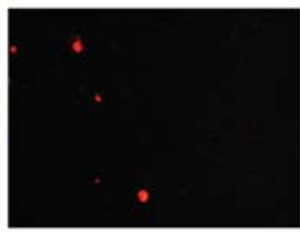

siNC

$+\mathrm{CDDP}$

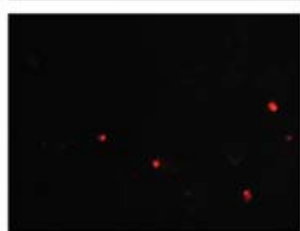

siRNA.

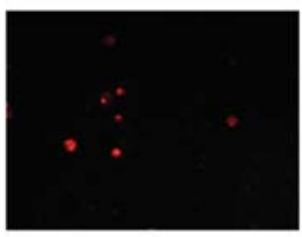

siRNA

+CDDP

Figure 4. Survivin silencing and CDDP induce apoptosis. (A) Fluorescence staining of nuclei using Hoechst 33342 and propidium iodide (PI), $12 \mathrm{~h}$ after treatment with negative control siRNA $(50 \mu \mathrm{M})$, negative control siRNA $(50 \mu \mathrm{M})+$ CDDP $(1 \mu \mathrm{M})$, siRNA for survivin $(50 \mu \mathrm{M})$, and siRNA for survivin $(50 \mu \mathrm{M})+$ CDDP $(1 \mu \mathrm{M})$. (B) Percentage of apoptotic cells, $12 \mathrm{~h}$ after treatment. Data are expressed as the mean \pm SEM ( $\mathrm{n}=4)$. (C) CCK-8 cell proliferation assay of HCC cells. Data are expressed as the mean $\pm \operatorname{SEM}(n=3)$.

control siRNA or siRNA for survivin. However, the expression level was similar between cells treated with negative control siRNA and siRNA for survivin, indicating that survivin did not affect phosphorylation of Akt in cells in the absence of treatment with CDDP (Fig. 5C). There was no significant difference of XIAP expression between cells treated with negative control siRNA or siRNA for survivin (Fig. 5D).

Regulation of survivin by PI3K/Akt. Rat HCC cells were treated with $25 \mu \mathrm{M}$ LY294002, phosphoinositide-3 kinase inhibitor, to elucidate the relationship between survivin and PI3K. LY294002 blocked the expression of survivin (Fig. 6A).

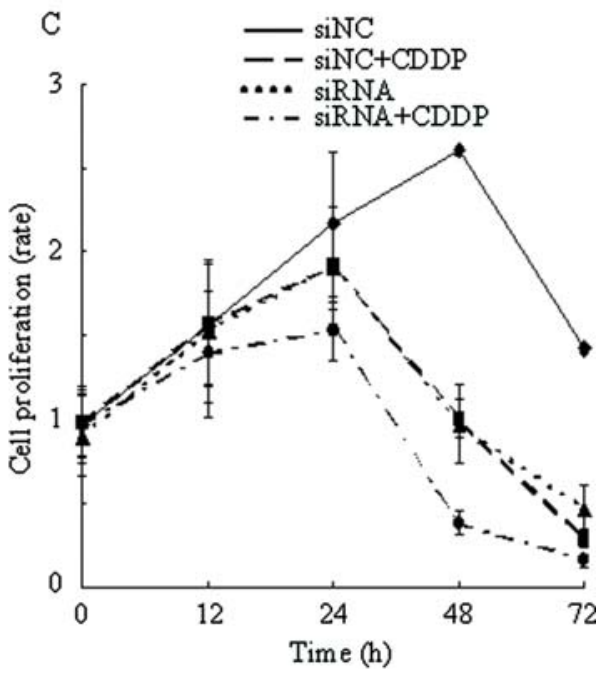

Similarly, expression of phospho-Akt was down-regulated in cells treated with LY294002 compared to those with treated with DMSO, in cells treated with/without CDDP (Fig. 6B). On the other hand, expression of XIAP was up-regulated in cells treated with LY294002 compared to those with treated with DMSO, and LY294002 increased expression of XIAP in cells treated with CDDP (Fig. 6C).

\section{Discussion}

We confirmed overexpression of survivin in DEN-induced rat $\mathrm{HCC}$ in vivo and in DEN-induced rat HCC cells in vitro. 
A.

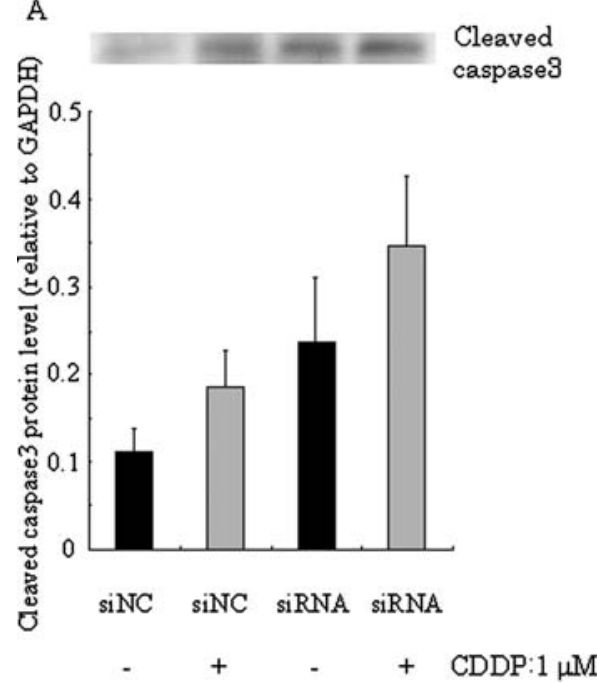

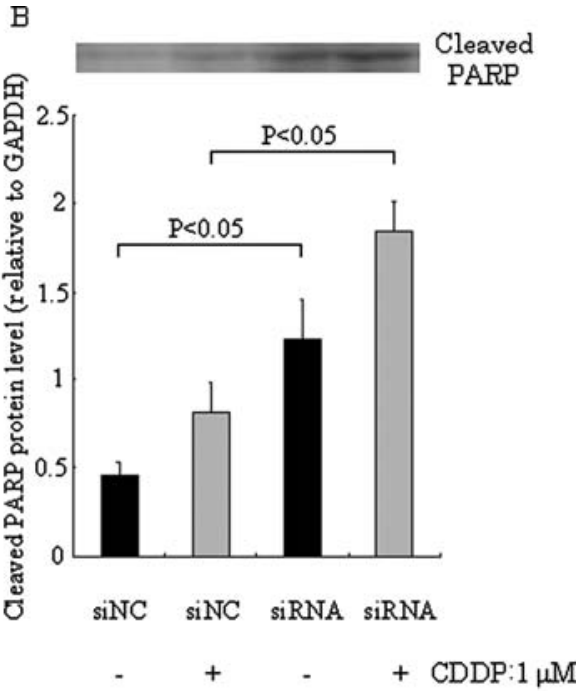

$\mathrm{D}$
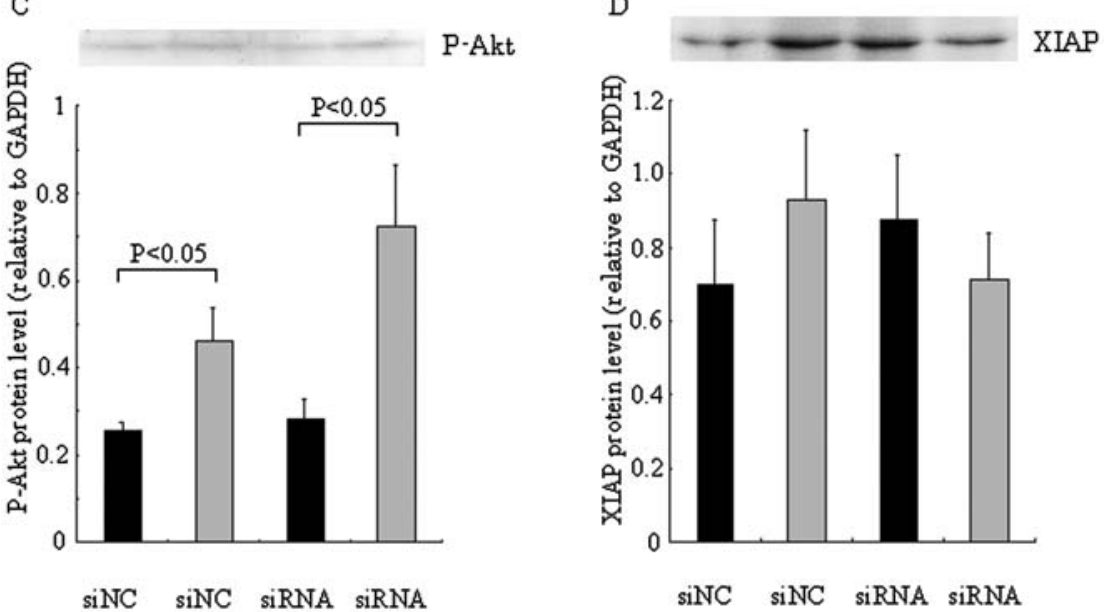

$+\quad \mathrm{CDDP}: 1 \mu \mathrm{M}$

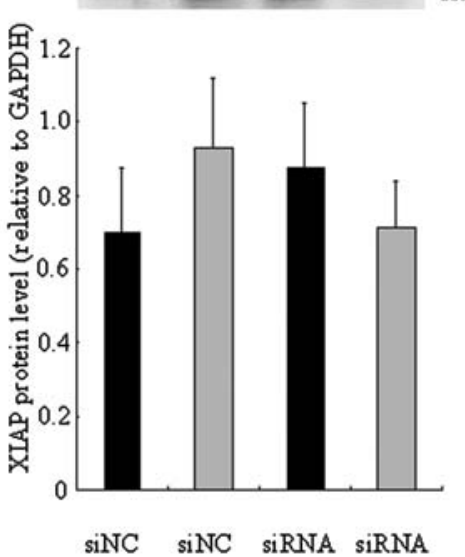

$+\operatorname{CDDP}: 1 \mu \mathrm{M}$

Figure 5. siRNA for survivin and CDDP induce apoptosis. Western blot analysis of cleaved caspase-3 (A), cleaved PARP (B), phospho-Akt (C) and XIAP (D) in HCC cells, $24 \mathrm{~h}$ after treatment. Data are expressed as the mean $\pm \operatorname{SEM}(n=4)$.

There was little survivin expression in non-tumor liver tissues from rat treated with DEN. Overexpression of survivin occurs frequently during cellular promotion of malignant neoplasms and has been identified as a negative prognostic factor in various cancer types $(8,14,16)$. In our study, suppression of survivin expression in rat HCC cells treated with siRNA for survivin attenuated cell proliferation of cancer cells. Survivin was overexpressed in rat HCC cells treated with CDDP, which was down-regulated by treatment with siRNA for survivin. Furthermore, siRNA for survivin sensitized rat HCC cells to CDDP-induced apoptosis. Our data show that CDDP or siRNA for survivin induced apoptosis in rat HCC cells, and that expression of survivin is regulated by the PI3K/Akt pathway, which has recently emerged as being frequently activated in various cancer types. Our results concur with previous reports. Olie et al demonstrated that targeting survivin has the potential to induce apoptosis and to increase the sensitivity to chemotherapy in lung cancer cells (28). Yang et al demonstrated that siRNA targeting survivin has the potential to increase the sensitivity of drug-resistant lung cancer cells to anticancer drugs (29). On the other hand, our results indicated that XIAP, one of the major members of the IAP families, was not involved in the regulation of survivin. It has been reported that survivin may block apoptosis by inhibiting caspase- 3 and caspase- 7 activities directly $(5,30)$. We also identified increased cleaved caspase- 3 levels, which indicates activation of caspase-3, in cells treated with siRNA for survivin.

Akt is a key mediator of the PI3K/Akt signaling pathway and is located at an intersection of multiple pathways that have been implicated in cell proliferation, survival, transcription and metabolic processes (31). Inhibition of the PI3K/Akt signaling pathway using the PI3K inhibitor (LY 294002) blocks growth and induces apoptosis (32). While the activity of Akt is tightly linked to PI3K activation, other factors can directly act on Akt to stabilize its oncogenic function. Previous studies have demonstrated that survivin expression was upregulated in the human HCC cell line, Hep3B, with CDDP treatment $(33,34)$. Furthermore, we demonstrated that CDDP up-regulated survivin expression in the rat HCC cell line 
A
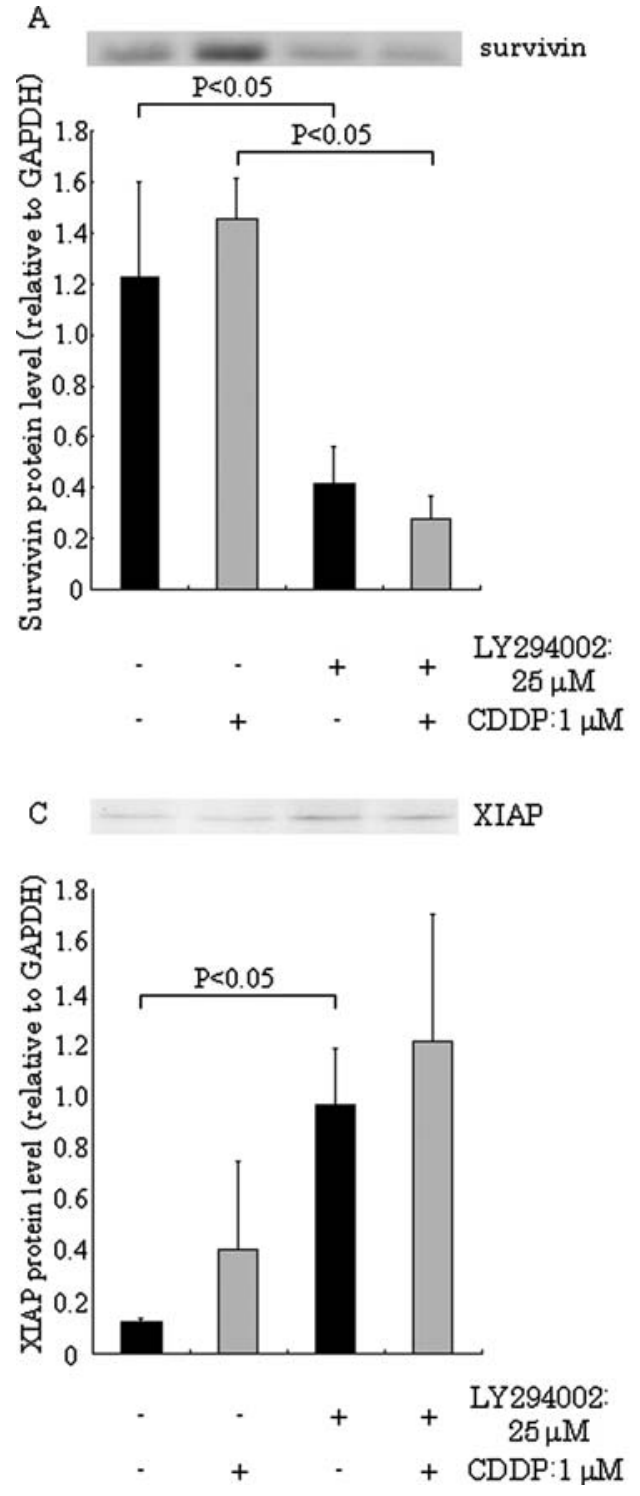

K-251 and that CDDP also activated Akt, resulting in increased survivin and p-Akt levels. Inhibition of the PI3K/Akt pathway decreased overexpression of survivin induced by CDDP and sensitized HCC to CDDP. Therefore, we concluded that survivin is regulated by the PI3K/Akt pathway and that inhibition of survivin expression with siRNA sensitized HCC cells to CDDP-induced apoptosis via the PI3K/Akt-dependent pathway. However, whether PI3K/Akt up-regulates survivin directly, or indirectly remains to be investigated.

We demonstrated that overexpression of survivin and its anti-apoptotic activity in rat HCC cells were regulated by PI3K/Akt signaling. These findings have significant clinical implications, since they provide direct evidence that CDDP itself can trigger resistance in HCC cells which can diminish its therapeutic efficacy. However, inhibition of the PI3K/ Akt pathway may have clinical limitations, because of their essential function in all types of cells in a complicated largely unresolved signaling network, which would reduce tumorspecificity. Our results demonstrated that survivin-specific siRNA down-regulates the overexpression of survivin induced by CDDP, and sensitize HCC cells to CDDP-induced apoptosis. The trans-catheter arterial chemo-embolization therapy

\section{B}

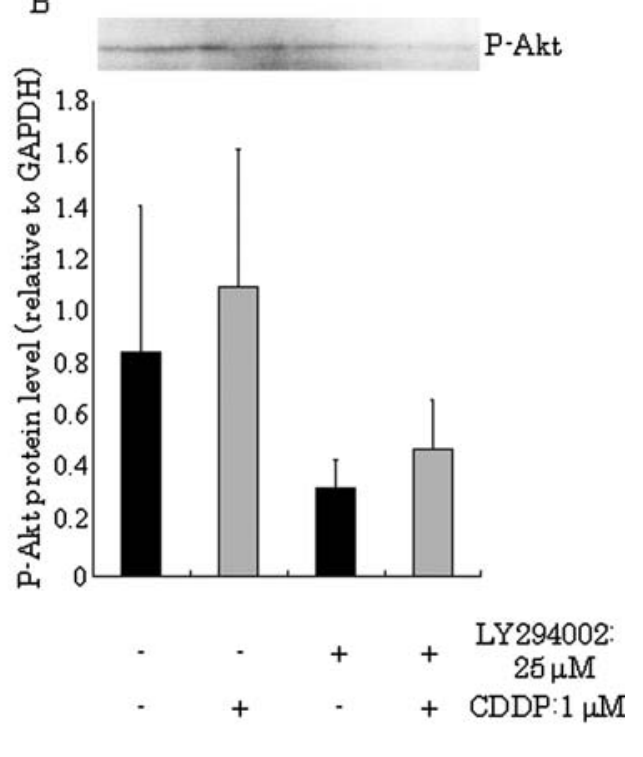

Figure 6. Regulation of survivin by PI3K/Akt. Western blot analysis of survivin (A), phospho-Akt (B) and XIAP (C) in HCC cells, after $24 \mathrm{~h}$ treatment with DMSO, CDDP $(1 \mu \mathrm{M})$, LY294002 $(25 \mu \mathrm{M}), \mathrm{LY} 294002(25 \mu \mathrm{M})+$ $\operatorname{CDDP}(1 \mu \mathrm{M})$. Data are expressed as the mean \pm SEM $(\mathrm{n}=4)$.

has already been applied for practical use, and we previously reported that hydro-administration of an siRNA expressing plasmid into the hepatic artery was a valid method for targeting rat HCC (26). Combination therapy of trans-catheter arterial chemo-embolization and siRNA for survivin, or hydro-administration injection and siRNA for survivin may be beneficial in the treatment of HCC. Furthermore, non-cancerous liver tissues may not responce to siRNA for survivin because they do not endogenously express survivin. Therefore, downregulation of survivin has the potential to enhance the efficacy of chemotherapy in the treatment of HCC and may have significant clinical impact.

\section{References}

1. Di Bisceglie AM: Epidemiology and clinical presentation of hepatocellular carcinoma. J Vasc Interv Radiol 13: S169-S171, 2002.

2. Montalto G, Cervello M, Giannitrapani L, Dantona F, Terranova A and Castagnetta LA: Epidemiology, risk factors, and natural history of hepatocellular carcinoma. Ann N Y Acad Sci 963: 13-20, 2002.

3. Igney FH and Krammer PH: Death and anti-death: tumour resistance to apoptosis. Nat Rev Cancer 2: 277-288, 2002. 
4. Reed JC: The Survivin saga goes in vivo. J Clin Invest 108: 965-969, 2001.

5. Tamm I, Wang Y, Sausville E, et al: IAP-family protein survivin inhibits caspase activity and apoptosis induced by Fas (CD95), Bax, caspases, and anticancer drugs. Cancer Res 58: 5315-5320, 1998.

6. Altieri DC: Validating survivin as a cancer therapeutic target. Nat Rev Cancer 3: 46-54, 2003.

7. Song Z, Yao X and Wu M: Direct interaction between survivin and Smac/DIABLO is essential for the anti-apoptotic activity of survivin during taxol-induced apoptosis. J Biol Chem 278: 23130-23140, 2003.

8. Monzo M, Rosell R, Felip E, et al: A novel anti-apoptosis gene: Re-expression of survivin messenger RNA as a prognosis marker in non-small-cell lung cancers. J Clin Oncol 17: 2100-2104, 1999.

9. Lu B, Mu Y, Cao C, et al: Survivin as a therapeutic target for radiation sensitization in lung cancer. Cancer Res 64: 2840-2845, 2004.

10. Tanaka K, Iwamoto S, Gon G, Nohara T, Iwamoto M and Tanigawa N: Expression of survivin and its relationship to loss of apoptosis in breast carcinomas. Clin Cancer Res 6: 127-134, 2000.

11. Pennati M, Colella G, Folini M, Citti L, Daidone MG and Zaffaroni N: Ribozyme-mediated attenuation of survivin expression sensitizes human melanoma cells to cisplatin-induced apoptosis. J Clin Invest 109: 285-286, 2002.

12. Satoh K, Kaneko K, Hirota M, Masamune A, Satoh A and Shimosegawa T: Expression of survivin is correlated with cancer cell apoptosis and is involved in the development of human pancreatic duct cell tumors. Cancer 92: 271-278, 2001.

13. Kato J, Kuwabara Y, Mitani M, et al: Expression of survivin in esophageal cancer: correlation with the prognosis and response to chemotherapy. Int J Cancer 95: 92-95, 2001.

14. Kawasaki H, Altieri DC, Lu CD, Toyoda M, Tenjo T and Tanigawa N: Inhibition of apoptosis by survivin predicts shorter survival rates in colorectal cancer. Cancer Res 58: 5071-5074, 1998.

15. Wang QW, Lu HL, Song CC, Liu H and Xu CG: Radiosensitivity of human colon cancer cell enhanced by immunoliposomal docetaxel. World J Gastroenterol 11: 4003-4007, 2005.

16. Nakagawara A: Molecular basis of spontaneous regression of neuroblastoma: role of neurotrophic signals and genetic abnormalities. Hum Cell 11: 115-124, 1998.

17. Zaffaroni $\mathrm{N}$ and Daidone MG: Survivin expression and resistance to anticancer treatments: perspectives for new therapeutic interventions. Drug Resist Updat 5: 65-72, 2002.

18. Carter BZ, Milella M, Altieri DC and Andreeff M: Cytokineregulated expression of survivin in myeloid leukemia. Blood 97: 2784-2790, 2001.

19. Papapetropoulos A, Fulton D, Mahboubi K, et al: Angiopoietin-1 inhibits endothelial cell apoptosis via the Akt/survivin pathway. J Biol Chem 275: 9102-9105, 2000.

20. Fornaro M, Plescia J, Chheang S, et al: Fibronectin protects prostate cancer cells from tumor necrosis factor-alpha-induced apoptosis via the AKT/survivin pathway. J Biol Chem 278: 50402-50411, 2003
21. Ling $X$, Bernacki RJ, Brattain MG and Li F: Induction of survivin expression by taxol (paclitaxel) is an early event, which is independent of taxol-mediated G2/M arrest. J Biol Chem 279: 15196-15203, 2004.

22. Wang HQ, Quan T, He T, Franke TF, Voorhees JJ and Fisher GJ: Epidermal growth factor receptor-dependent, NF-kappaBindependent activation of the phosphatidylinositol 3-kinase/Akt pathway inhibits ultraviolet irradiation-induced caspases-3, -8, and -9 in human keratinocytes. J Biol Chem 278: 45737-45745, 2003.

23. Hayakawa J, Ohmichi M, Kurachi H, et al: Inhibition of BAD phosphorylation either at serine 112 via extracellular signalregulated protein kinase cascade or at serine 136 via Akt cascade sensitizes human ovarian cancer cells to cisplatin. Cancer Res 60: 5988-5994, 2000.

24. Gerolami R, Cardoso J, Bralet MP, et al: Enhanced in vivo adenovirus-mediated gene transfer to rat hepatocarcinomas by selective administration into the hepatic artery. Gene Ther 5: 896-904, 1998.

25. Bilbao R, Bustos M, Alzuguren P, et al: A blood-tumor barrier limits gene transfer to experimental liver cancer: the effect of vasoactive compounds. Gene Ther 7: 1824-1832, 2000.

26. Tada M, Hatano E, Taura K, et al: High volume hydrodynamic injection of plasmid DNA via the hepatic artery results in a high level of gene expression in rat hepatocellular carcinoma induced by diethylnitrosamine. J Gene Med 8: 1018-1026, 2006.

27. Escobedo $J$ and Koh TJ: Improved transfection technique for adherent cells using a commercial lipid reagent. Biotechniques 35: 936-940, 2003.

28. Olie RA, Simoes-Wust AP, Baumann B, et al: A novel antisense oligonucleotide targeting survivin expression induces apoptosis and sensitizes lung cancer cells to chemotherapy. Cancer Res 60: 2805-2809, 2000.

29. Yang $\mathrm{H}, \mathrm{Fu} \mathrm{JH}, \mathrm{Hu} \mathrm{Y}$, et al: Influence of siRNA targeting survivin on chemosensitivity of H460/cDDP lung cancer cells. J Int Med Res 36: 734-747, 2008.

30. Ambrosini G, Adida C and Altieri DC: A novel anti-apoptosis gene, survivin, expressed in cancer and lymphoma. Nat Med 3: 917-921, 1997.

31. Lawlor MA and Alessi DR: PKB/Akt: a key mediator of cell proliferation, survival and insulin responses? J Cell Sci 114: 2903-2910, 2001.

32. Krystal GW, Sulanke G and Litz J: Inhibition of phosphatidylinositol 3-kinase-Akt signaling blocks growth, promotes apoptosis, and enhances sensitivity of small cell lung cancer cells to chemotherapy. Mol Cancer Ther 1: 913-922, 2002.

33. Asselin E, Mills GB and Tsang BK: XIAP regulates Akt activity and caspase-3-dependent cleavage during cisplatin-induced apoptosis in human ovarian epithelial cancer cells. Cancer Res 61: 1862-1868, 2001.

34. Hoffman WH, Biade S, Zilfou JT, Chen J and Murphy M: Transcriptional repression of the anti-apoptotic survivin gene by wild type p53. J Biol Chem 277: 3247-3257, 2002. 